\title{
La tzedaká en la ética de E. Lévinas y A. Salomon: hacia una ética de mínimos para el trabajo social
}

\section{Francisco Idareta-Goldaracena}

Departamento de Trabajo Social, Universidad Pública de Navarra

<francisco.idareta@unavarra.es>

\begin{abstract}
Artikulu honetako xedea da Emmanuel Levinas filosofo judutar eta Alice Salomon gizartelangilearen justizia sozialaren kontzepzioetan erabilitako tzedaka identifikatzea, eta horretaz gain, gizarte-langintzarako oinarri izan daitezkeen arlo moraleko gutxiengo komun batzuk ezartzeko osagai batzuk identifikatzea. Hori dela-eta, lehenik eta behin aztertuko dugu judaismoarentzako etikak duen garrantzia. Horren ondoren, konparazio bat burutuko dugu, bertan identifikatuz tzedaka-ren praktika eta gizarte-langintzarako gutxiengo etiko batzuk betetzeko baliabide izan daitezkeen osagai horiek. Aldi berean, errukia eta justizia soziala tzedaka-ren osagai direnez, horiek izango dira atal bakoitza egituratzen duten kontzeptuak.
\end{abstract}

\section{GAKO-HITZAK:}

E. Levinas, A. Salomon, justizia soziala, etika, tzedaka, duintasuna.
El presente artículo pretende identificar la tzedaká en las concepciones de justicia social del filósofo judío Emmanuel Lévinas y de la trabajadora social Alice Salomon, así como aquellos elementos que puedan conformar las bases para el establecimiento de una ética de mínimos morales comunes en trabajo social. Por ello, primeramente, analizaremos la importancia de la ética en el judaísmo. Seguidamente, profundizaremos en las concepciones de justicia social de Lévinas y de Salomon. A continuación, las compararemos, identificando en ellas la práctica de la tzedaká y aquellos elementos que pudiesen conformar una ética de mínimos para el trabajo social. A su vez, y dado que la compasión y la justicia social son los elementos que componen la tzedaká, serán los que estructurarán cada uno de los apartados.

\section{Palabras clave:}

E. Lévinas, A. Salomon, justicia social, ética, tzedaká, dignidad. 


\section{Introducción}

Cuando en una sociedad se transgreden los límites de la dignidad humana sin reparar en sus alarmantes consecuencias sociales (trato inhumano a los refugiados, trata de mujeres, explotación infantil, maltrato a personas mayores, desprotección y empobrecimiento de las personas más desfavorecidas), quizás es porque no sólo debamos apelar a la protección y a la garantía de protección que el Estado debe proveernos legalmente, sino que también debamos reflexionar sobre su contenido y el imperativo ético que subyace a dicha concepción.

¿Por qué se transgrede ese sacrosanto umbral que salvaguarda la humanidad de cada persona? ¿Es porque no se aplica la ley adecuadamente? ¿Es porque ésta se encuentra indebidamente planteada? ¿Es porque la concepción de dignidad sobre la que se asienta la legislación positiva que la protege no se adapta a los nuevos tiempos? ¿Es porque no hemos educado a las y los ciudadanos en la asunción de la responsabilidad de los problemas sociales ajenos? ¿Es porque, habida cuenta de la connivencia existente, no hay interés en formar e informar en la importancia de la reflexión y de la creación de una ética de mínimos comunes que tenga la dignidad como fundamento inalienable? Desde el punto de vista moral, ¿en qué tipo de sociedades vivimos?, ¿se forma a la ciudadanía en el pluralismo moral?

Según Cortina (2010), a lo largo de la historia se han dado tres tipos de sociedades: moralmente monistas, moralmente laicistas y moralmente pluralistas. Las primeras se caracterizan por poseer una única ética de máximos; las segundas, por promover varias éticas de máximos sin haber podido alcanzar el consenso para una ética de mínimos morales comunes; mientras que la tercera se caracteriza no sólo por promover modos de vida en plenitud, sino por ser capaz de lograr el consenso suficiente para establecer una ética de mínimos morales comunes.

Las éticas de máximos son formas de vida feliz que cada ciudadano elige y que no se deben exigir ni imponer a los demás, mientras que la ética de mínimos la componen valores exigibles a cada uno de los seres humanos que indican el umbral por debajo del cual el trato que dispensamos es inmoral e inhumano. Dicho de otro modo, las éticas de máximos son propuestas de vida feliz, son opciones privadas, no imponibles e intransferibles, mientras que las éticas de mínimos son propuestas de protección básica de la dignidad humana (contra la miseria, la pobreza), tienen carácter de exigencia pública y, por consiguiente, constituyen una obligación moral para todo ser humano.

En España, el pluralismo moral sigue siendo ficticio, ya que predomina una moral utilitarista y un politeísmo axiológico basado en la fe y los sentimientos (Cortina, 2010), que dificultan el esclarecimiento de todos los interrogantes anteriormente planteados, a la vez que facilitan la transgresión del umbral de la dignidad humana. Del mismo modo, y aunque el trabajo social posea una larga tradición ética en nuestro país, su tendencia al principialismo ético y su vocación eminentemente práctica le podrían impedir aunar esfuerzos para reflexionar en profundidad sobre la construcción de nuevas bases sobre las que asentar una ética de mínimos (Idareta, 2011, 2012).

Precisamente por ello, consideramos que hay que ahondar en nuevos fundamentos que propongan sentidos y significados de dignidad humana diferentes, complementarios o alternativos a los ya existentes, para una ética de mínimos en el trabajo social. Sentidos y significados diferentes de dignidad humana que contribuyan a remarcar las líneas rojas que nunca debemos transgredir en nuestras intervenciones sociales. Nuevos sentidos y significados que garanticen el trato digno de las y los profesionales a las personas usuarias y que, a su vez, les posibiliten a éstas la toma de conciencia de su propia dignidad humana y de la de los demás.

Por todo ello, con este artículo pretendemos abrir nuevas vías reflexión y plantear nuevos elementos de discusión que puedan ayudar a solventar el esclarecimiento de las líneas rojas que se transgreden en nuestra sociedad con total impunidad en relación al concepto de la dignidad humana. No en vano, de esta concepción de dignidad se derivan, en gran medida, la construcción de políticas sociales que marcan los límites de nuestra intervención social para con las personas usuarias. Para ello, primeramente, ahondaremos en las concepciones de justicia social de E. Lévinas y A. Salomon, seguidamente identificaremos en éstas la práctica de la tzedaká judía y aquellos elementos que nos ayuden a construir las bases de una ética de mínimos morales comunes para la profesión.

\section{La ética en el judaísmo: la tzedaká}

Desde sus orígenes, el judaísmo se ha visto obligado a preocuparse por los problemas personales y sociales de los miembros de su comunidad. No hay que olvidar que hasta 1948 el pueblo judío ha carecido de Estado que se hiciese cargo de solventar este tipo de dificultades estructurales y personales (educación, salud). De ahí que, desde los tiempos de Moisés, se haya venido sistematizando la reflexión sobre estas necesidades sociales, así como la búsqueda de soluciones concretas a aquéllas. A esta ausencia de Estado, habría que añadir los infortunios que han acompañado al pueblo judío a lo largo de su historia, de entre los que cabe destacar el holocausto nazi.

Sin Estado, errantes por el mundo y en situación cuasipermanente de vulnerabilidad, resultaba imprescindible la ayuda mutua para la supervivencia (Baeck, 1960). De ahí que el cumplimiento de la conducta moral de cada miembro de la comunidad haya adquirido mayor relevancia que el contenido 
de las creencias religiosas (Fackenheim, 2005). No obstante, el sustrato del que parten los principios éticos es eminentemente religioso, sin que puedan llegar a distinguirse la ética y la ley judía (Kellner, 1995). De hecho, por la importancia otorgada al establecimiento de normas éticas y la regulación permanente de las relaciones de los miembros de la comunidad, el judaísmo no sólo es considerado como un sistema ético, sino que adquiere los visos de una ética pública, de una ética social (De Lange, 1996; Cohen, 2004).

Por todo ello, el judaísmo posee una cosmovisión única, cuyos elementos detallamos a continuación. Ya que el egoísmo, la avaricia y la idolatría eran una amenaza para un pueblo sin Estado, se concibe que cada ser humano tiene la obligación moral de preocuparse por el prójimo y que debe ser especialmente solidario con los más pobres, a los que se dedicará con sentimiento de generosidad. En este sentido, para evitar los conflictos, la explotación, la esclavitud, la opresión o la exclusión de los miembros más vulnerables de la comunidad, se insta a cada ciudadano y a la propia sociedad a que asuma su responsabilidad en la lucha por las desigualdades sociales.

Los mandamientos que instauraría el judaísmo para evitar el caos en la sociedad podrían sintetizarse en uno: ayudar de corazón a los más débiles, haciendo copartícipe a la sociedad en la lucha contra las desigualdades sociales. Ese mandamiento adquiere el nombre de tzedaká y, como se señala en el Talmud Babilónico (Baba Bathra, 9a), es el mandamiento que combina todos los anteriores y posee el mismo grado de importancia que todos ellos. Hacer tzedaká consiste en la exigencia moral de reparar las injusticias, ayudando al pobre con sentimiento de generosidad y con responsabilidad (Kliksberg, 2000).

Hacer tzedaká es hacer justicia de corazón. De ahí que Maimónides elaborase una escala con los ocho grados de la tzedaká: cuando ayudamos al pobre sin ganas, por obligación, a regañadientes, equivale al grado más bajo; mientras que cuando ayudamos al pobre a ayudarse a sí mismo, a que pueda valerse por sí mismo, equivale al grado más alto ${ }^{1}$. Efectivamente, para el judaísmo es muy importante el sentimiento que acompañe a cada acción, ya que concibe que cada sujeto imita la desinteresada acción bondadosa de la divinidad, tras de la que se

${ }^{1}$ Kliksberg (2000: 46) describe cada uno de los grados de la escala formulada por Maimónides: "el más alto grado es ayudar a un hombre que lo necesita, ofreciéndole un regalo o un préstamo, entrando en la sociedad con él, o proveyéndole de trabajo, de modo que pueda llegar a autosostenerse; el segundo grado más alto es aquel en el que el que da y el que recibe no saben el uno del otro; el tercer grado es cuando el dador conoce al receptor, pero éste no conoce al dador; el cuarto grado es aquel en que quien recibe conoce al dador, pero éste no conoce a quien recibe; el quinto grado es cuando el dador pone su ayuda en manos del pobre sin que éste se la haya pedido; el sexto grado es cuando el dador pone su ayuda en manos del pobre después de que éste se lo ha solicitado; el séptimo grado es cuando el dador da menos de lo que debería, pero lo hace con todo agrado; el octavo grado es aquel en que el dador da con resentimiento". esconde el amor infinito por sus criaturas (Cohen, 2004; Kellner, 1995).

Por todo ello, para el judaísmo la compasión y la justicia son valores fundamentales. La compasión es un sentimiento que nos descentra, que nos hace salir de nosotros mismos para ir al encuentro del necesitado. Es la emoción que sentimos frente a la extrema vulnerabilidad de los más débiles y que acompañará a la acción que emprendamos para reparar la injusticia. La compasión es una forma de amor que nos posibilita la apertura a la realidad del necesitado, al que, desde entonces, comenzamos a mirar cara a cara.

Por lo tanto, la compasión es aquella emoción que inicia el proceso de responsabilidad social de cada sujeto. De hecho, cabría decir que, para el judaísmo, es el modo en que cada sujeto se subjetiva como humano: siento que el otro me necesita y respondo para reparar la injusticia que lo oprime, que lo hace sufrir. Del mismo modo, el sentimiento de compasión frente al sufrimiento ajeno hace consciente nuestra propia vulnerabilidad, descubriendo así que necesitamos de las demás personas.

Somos humanos en tanto en cuanto necesitamos ayuda a la par que ayudamos al otro, rompiendo de ese modo con el paradigma de autosuficiencia y de invulnerabilidad sobre el que se erige la filosofía occidental. Por ello, experimentar la vulnerabilidad propia frente a la vulnerabilidad del prójimo instaura en cada sujeto el imperativo ético de luchar por la injusticia. Sentir la vulnerabilidad del pobre instaura en cada conciencia la responsabilidad en la gestión de la justicia social.

La justicia es un mandamiento absoluto a la par que el ideal por excelencia en el judaísmo, cuya particularidad radica en que ha de ser completada y animada por el afecto del amor. Esta concepción tiene mucho que ver con el libro del Éxodo, en el que se explica que Dios lucha por los oprimidos y por liberarlos de la esclavitud de su sufrimiento. De hecho, para impedir la opresión del pueblo judío, Dios entregó a Moisés las tablas de la ley. Una ley que tiene como objetivo la instauración universal de la moral en la sociedad, cuya observancia es obligatoria si se quiere alcanzar el perfeccionamiento humano (Cohen, 2004; Kellner, 1995).

Así es como el judaísmo concibe la justicia: como fundamento del Estado y como "centro de gravedad de la ética social” (Cohen, 2004: 332). Por ello, la Alianza del pueblo judío trajo consigo una regulación de las relaciones de los miembros de la comunidad judía que neutralizaba cualquier manifestación de egoísmo. De hecho, las leyes instaban a reconocer y a respetar la autoridad del juez, así como a abstenerse de idolatrar a falsos dioses, de blasfemar, del asesinato, del libertinaje, del consumo de carne animal y de la apropiación violenta e indebida (Lévinas, 1994). 
Después de que el juez dictase sentencia e hiciese cumplir escrupulosamente la ley, exigía que la sociedad tuviese la misma consideración que tenía del reo antes de ser culpable y de que se le impusiera la pena. Esta particular concepción judía de justicia se encuentra ejemplificada en el consejo de sabios que conformaba el sanedrín. Mientras juzgaban al reo, los jueces no lo miraban al rostro para evitar sentir ningún afecto por él; únicamente tenían en consideración la tipificación de la pena y la sentencia que debían dictar y hacer cumplir. No obstante, tras la sentencia, los jueces volvían a reparar en su rostro, en lo que hacía singular al sujeto, devolviéndole así su condición de persona y exigiendo a la sociedad que fuese tratado como tal (Lévinas, 1996).

Pese a que la justicia, segunda virtud de primer grado, adquiera en el judaísmo el significado de beneficencia, de hacer el bien al necesitado, aquélla no logra diluirla. De hecho, gracias a la justicia, esta beneficencia se universaliza. Es de este modo como justicia y beneficencia se convierten en el ideal del ser humano (Cohen, 2004). En cualquier caso, la tzedaká consiste en vivir conforme a la Ley, no porque ésta lo indique, sino porque es fundamental para reparar y transformar el mundo². La tzedaká es uno los más importantes mandamientos de la Torá, que exige ayudar al necesitado (que, en la Biblia, adquiere el rostro de la viuda, el huérfano, el extranjero, el pobre, el perdedor), combinando justicia y amor: justicia como amor o amor como justicia, siendo ambos intercambiables (Cohen, 2004).

Así, la tzedaká está constituida por tres tipos de justicia -la económica, la social y la política-, y únicamente lograremos la paz si cumplimos con todas ellas (Braverman, 2014). Gracias a la justicia económica conseguimos luchar contra el egoísmo y el individualismo, promoviendo el respeto, la proximidad y la responsabilidad con el más necesitado para erradicar la pobreza y la miseria de la sociedad. Como no es suficiente con condenar la injusticia, se hace necesario implantar la justicia social, que aboga por proteger y garantizar el empoderamiento, la libertad, la fraternidad y la igualdad de todos y cada uno de los ciudadanos. Ciudadanos que, siendo singulares, irrepetibles e incomparables, han de ser comparados, medidos y juzgados por las leyes del Estado. De ahí que la justicia que garantiza el cumplimiento de tales leyes sea la justicia política. Una justicia que tiene como finalidad humanizar las funciones de las instituciones del Estado y vigilar su correcta observancia. De ese modo, sin justicia política, no se podría garantizar el cumplimiento de la ley; sin justicia social, la sociedad estaría abocada a la desigualdad y a la esclavitud; y sin justicia económica, reinaría el egoísmo como inicio de la guerra hobbesiana de todos contra todos.

${ }^{2} \mathrm{~A}$ esta responsabilidad que se contrae cuando nos concienciamos de que con nuestra conducta ayudamos a evitar consecuencias sociales indeseables se le denomina tikún olam.
En definitiva, para ponerse en el camino de la paz, resulta fundamental: 1) formar a la ciudadanía en el paradigma de la vulnerabilidad humana, del que se desprende la exigencia de respetar al desvalido y de hacerse cargo de su sufrimiento y de su precariedad; 2) garantizar tanto la incorruptibilidad de magistrados, jueces y fiscales, a través de una rigurosa formación ética que humanice el proceso de aplicación de la ley, como la vigilancia del correcto funcionamiento de las instituciones del Estado; y 3) salvaguardar el trato humano que reciban los ajusticiados tras la aplicación de la pena.

En este sentido, según Cohen (2004), cuando se logra la paz, para el judaísmo dos son los signos que la delatan: la emoción y la alegría. La primera denota la no indiferencia de la persona ante la injusticia, la conmoción de entrañas por el sufrimiento del necesitado y, por todo ello, es la que ejerce "como un correctivo de la justicia" (Cohen, 2004: 352). La segunda es la capacidad de regocijarse y aliarse con el necesitado, de compartir con él los buenos momentos, y no sólo los malos.

\section{La ética y la justicia social en la obra de Emmanuel Lévinas}

Emmanuel Lévinas (1906-1995) fue uno de los filósofos más prolíficos del siglo XX. Desde muy pequeño conoció las atroces consecuencias de la guerra, ya que pese a nacer y vivir en Kaunas (Lituania), tuvo que exiliarse con su familia a Jarkov (Ucrania) durante la I Guerra Mundial. Tras su vuelta a casa, decide estudiar Filosofía en la Universidad de Estrasburgo. Reconoce en numerosas ocasiones que su nacionalidad francesa, adquirida en 1930, le salvará la vida, ya que lo destinaron como soldado francés a un campo de trabajo entre 1940 y 1945. Posteriormente, fue director y profesor de la Escuela Normal Israelí Oriental (ENIO) en París (Critchley, 2004).

Lévinas realiza su aportación filosófica inspirándose en el judaísmo (Sucasas, 2006), aunando en ella, no sin dificultades, la tradición griega y la hebrea. Pese a que la principal aportación de Lévinas fue efectuada en las décadas de los sesenta y setenta (Lévinas, 2002, 2003), todavía hoy se continúa recurriendo a su propuesta ética. Una propuesta que logra destilar, con una filosofía del más alto nivel, la ética judía de su inherente sustrato religioso. Una propuesta a través de la cual denuncia la tendencia a la aniquilación del Otro promovida por la preponderancia de la filosofía occidental. La suya es una ética sin sistema, no programática (Lévinas, 2000; Poirié y Lévinas, 2009). No obstante, existen propuestas que aproximan su ética al trabajo social, de entre las cuales nos basaremos en la de Idareta (2011, 2012).

Según Lévinas, el holocausto nazi fue originado por la preponderancia de la tradición griega en la filosofía occidental. Este filósofo judío fue testigo presencial de tal barbarie, aunque, por su 
nacionalidad francesa, logró librarse del destino que corrió gran parte de su familia, masacrada por los nazis. Para éstos, ser judío era motivo suficiente para ser aniquilado: de hecho, fue el motivo principal del exterminio sistemático de los judíos. No importaban las infinitas cualidades de la persona a la que se asesinaba. La violencia y el asesinato estaban justificados si no se era ario.

Por ello, Lévinas realiza una crítica radical de la primacía de la tradición griega en la filosofía occidental. Esta preponderancia promovía el egoísmo y el individualismo, así como relacionarse con el Otro a través del conocimiento que el yo adquiría de él. Sin la experiencia directa del Otro, que la filosofía occidental impide, el yo tiende a relacionarse con las ideas que se compone del Otro, reduciéndolo a aquéllas. Así, categorizándolo cognitivamente, es como el yo logra imponerse como dueño y señor, dando sentido y significación al Otro a su antojo, sin necesidad de contar con él en absoluto.

Por su parte, Lévinas defiende que el Otro tiene infinitas características y que, por lo tanto, es irreductible a las categorías que el yo lo haya podido ajustar. El Otro desborda siempre las categorías a las que pretendamos ajustarlo y, por ello, exige una apertura por parte de la persona que lo acoja. La apertura a la infinitud del Otro exige responsabilidad para con él, lo que significa ser sensible a sus necesidades antes que intentar conocerlo.

Lévinas critica que las consecuencias de basarnos en esa filosofía que prioriza al ser, a nuestro propio yo, es que tendemos a conocer al Otro y a ajustarlo a nuestras ideas. Pero el Otro, antes de que intentemos conocerlo, antes de que lo categoricemos, disfruta de su singularidad como persona, siendo poseedor de sus infinitos atributos.

Cuando categorizamos al Otro, lo violentamos, aunque sepamos que efectivamente el Otro es mucho más que las categorías a las que lo hemos reducido. La filosofía del ser brinda la superioridad a la persona que categoriza sobre la que es categorizada. Por el contrario, cuando la filosofía primera es la ética, la violencia cesa y, proporcionalmente, la exigencia del sujeto hacia el Otro se multiplica.

En este estado anterior a nuestra categorización cognitiva, el Otro se muestra tal cual es, libre de la opresión que ejercen sobre él nuestras categorías cognitivas. Y lo que es más importante: en este estado anterior a nuestra conceptualización cognitiva, el Otro nos exige respeto, despertando nuestra sensibilidad. No lo reclama verbalmente, sino conmoviendo nuestra entraña profunda a través de la expresión no verbal de su necesidad de ser ayudado.

Esta sensibilidad hace que sintamos al Otro antes que conocerlo y que nos demos cuenta de que esa experiencia sensible del Otro no es categorizable. De hecho, despertando nuestra sensibilidad es como el Otro nos traslada su situación de máxima vulnerabilidad. Conmoviendo nuestras entrañas antes de conocerlo, es decir, de corazón a corazón, el Otro nos traslada que, hasta ese momento, habíamos actuado de forma violenta con él pese a que él siempre se haya encontrado necesitado de ayuda.

Esto significa que cuando estamos el Otro y yo solos, debo ayudarlo: me debo enteramente a él. La irrupción del sufrimiento del Otro en mi sensibilidad despierta mi conciencia de su máxima vulnerabilidad. No obstante, cuando entre el Otro y yo aparece un tercero, Lévinas señala que se instaura la justicia y que hay que tipificar situaciones, calcular, medir, sopesar y juzgar a los ciudadanos. Esto, a efectos prácticos, significa que el peso de la responsabilidad para con el Otro, de la relación ética, ahora no sólo recae sobre una persona. Cuando se instaura la justicia, el Estado debe salvaguardar y garantizar que las personas en situación de máxima vulnerabilidad sean atendidas. Entre el yo y el Otro, aparece el juez, que debe garantizar las relaciones de igualdad.

No obstante, nunca se pierde la huella que el Otro deja en mí en la relación ética. De hecho, el valioso aprendizaje que el yo ha adquirido en la relación ética inicial con el Otro liderará todos los procesos de cálculo, medida, comparación y tipificación de aquél: el Otro, aunque lo categoricemos, siempre poseerá infinitas cualidades que lo hacen persona en ese estado anterior a toda conceptualización.

Así, mientras que la relación ética originaria se caracteriza por la asimetría entre el yo y el Otro, al instaurarse la justicia, la simetría caracteriza la relación con los demás: todos somos iguales ante la ley. Todos somos iguales ante la ley, pero a la vez, todos poseemos una singularidad única, diferente e irrepetible, que se debe salvaguardar. Por lo tanto, la simetría legal levinasiana se basa en aquella asimetría ética originaria a la que protege. Dicho de otro modo, según Lévinas, nunca desaparece la enseñanza que adquiere el yo en el encuentro ético originario con el Otro: también en la convivencia con el resto de ciudadanos, el yo continúa sintiéndose interpelado y responsable de los más necesitados, ya que rememora el momento en el que se sintió vulnerable y se conmocionó con el sufrimiento del Otro antes de poderlo conocer.

Esta brusca experiencia sensible del sufrimiento del Otro hace que nos concienciemos para que, en lo sucesivo, aunque lo categoricemos, reconozcamos que el Otro siempre disfrutará de sus infinitos atributos. Dicho de otro modo, nuestra sensibilidad ética es la que se mantendrá vigilante ante nuestras sucesivas categorizaciones del Otro, permitiendo que recordemos que el Otro es mucho más que las categorías a las que lo hemos reducido, de tal modo que, cuando categoricemos, nos acordemos de descategorizar al Otro.

La originalidad de la aportación filosófica de Lévinas radica en que considera imprescindibles tanto la 
tradición griega del logos categorizante como la tradición judía de la sensibilidad vigilante. Si la primera predomina sobre la segunda, se volvería a instaurar la violencia, al no haber instancia que se haga cargo de descategorizar lo categorizado: retornaría nuevamente el totalitarismo. Si únicamente se prioriza la segunda, se desvanecería el orden que instaura el logos y sus consecuencias serían, del mismo modo, devastadoras.

En este sentido, conscientes de que el judaísmo parece el sustrato sobre el que se sustenta la propuesta ética de Lévinas (Sucasas, 2006), señalaremos algunos términos filosóficos que poseen un marcado influjo religioso en su obra. Concretamente, nos referiremos a la compasión, la caridad, la justicia social y la paz. La compasión es el sentimiento que experimenta el yo frente al sufrimiento del Otro, mientras que la caridad es la responsabilidad infinita que surge como consecuencia de dicho encuentro. La compasión es la conmoción de mis entrañas por el sufrimiento ajeno, y la caridad es el amor por y para el Otro, o hacerme cargo de él.

La justicia social es el momento en el que se compara lo que es incomparable, en el que se categoriza aquello que no es categorizable. Cuando se protege la igualdad entre los ciudadanos, se es consciente de que cada uno de ellos es singular y, por tanto, poseedor de infinitas cualidades como persona. Un ejemplo de ello lo encontramos en los derechos humanos, que, desde la perspectiva levinasiana, son la traducción y la objetivación a categorías lingüísticas de la irreductible singularidad humana que preserva la ética.

No obstante, para Lévinas (1997), los derechos humanos que, como vemos, se fundamentan en una ética que los preserva, han de ser garantizados a la par que protegidos por el Estado. De ahí que la propuesta levinasiana establezca las bases preontológicas para la instauración de una ética de mínimos que sean garantizados por el Estado. Por ello, antes y como fundamento de las operaciones ontológicas (legislar, aplicar la ley, enjuiciar, diagnosticar, evaluar, catalogar) se encuentra la irreductibilidad de la alteridad humana.

Dicho de otro modo, desde esta perspectiva, la ética es la que salvaguarda la infinitud de la singularidad de la persona antes, durante y después de todas aquellas operaciones ontológicas de cálculo, medida y comparación (diagnóstico social, tipificación legal, enjuiciamiento, aplicación de la ley, generalización, abstracción, psicologización). De hecho, inspirándose en el sanedrín, Lévinas señala que la justicia social se ha de practicar con "rigor y misericordia" (1996: 126). Rigor a la hora de ajustarse objetiva e imparcialmente a la ley y de aplicar la norma sin afecto, sin preferencias. Y misericordia entendida como sensibilidad que debe humanizar y regular durante el juicio, aunque también antes y después de él, la relación con el reo, teniendo siempre muy presente su situación de vulnerabilidad humana. En aras de la humanización de la justicia, Lévinas dirá que "la misericordia atenúa los rigores de la Ley sin suspenderla” (Lévinas, 2004).

Así, el Estado que instaure esta justicia será el que se ponga en el camino de la paz. Una paz que Lévinas (2006b) entiende como despertar del sujeto a la precariedad del Otro. No obstante, ese despertar trae consigo la obsesiva y siempre inquietante responsabilidad vitalicia del sujeto por el necesitado, por lo que no estaremos en el camino de la paz si ésta consiste en prescindir del Otro, en que el Otro no nos moleste. Para lograr la paz, no es suficiente con la tradición griega, cuya prioridad es el ser y su conocimiento del Otro: es necesaria también la tradición hebrea, que pone su acento en la emoción de la experiencia surgida en la relación cara a cara con el Otro. Ambas son imprescindibles en el camino de la paz: emoción y conocimiento, sensibilidad y vigilancia, compasión y justicia.

\section{La ética y la justicia social en la obra de Alice Salomon}

Alice Salomon (1872-1948) ha sido una de las más importantes pioneras del trabajo social a escala mundial. Así lo atestiguan diferentes investigaciones realizadas sobre su vida y su obra (Feustel, 1997, 2000, 2004, 2006, 2011, 2012; Kuhlmann, 2000, 2001, 2007, 2008; Wieler, 1988, 1997; Lees, 2004; Schröder, 2010; Zeller, 1998; Nogal, 2008; Peyser, 1958). Fue la tercera de cinco hermanos en una familia judía no practicante. Más que probablemente, el hecho de ser judía y mujer marcarían el carácter de Salomon y no menos su destino, que en ningún caso estuvo exento de riesgos para ella.

Luchar por los más desfavorecidos estaba penado con la muerte, ya que, tras el ascenso de Hitler al poder, los recursos sociales estaban destinados a los arios y sanos. Además, ser mujer y defender la igualdad de derechos entre hombres y mujeres en una sociedad patriarcal le acarreó serios problemas 3 . No en vano, la 'Jane Addams alemana' fue perseguida por el Partido Nacionalsocialista por su condición de humanista, de feminista, de pacifista, de reformista social y de internacionalista. De hecho, gran parte de su obra fue destruida por los nazis, aunque se está realizando un considerable esfuerzo por recuperarla en su totalidad (Feustel, 1997, 2000, 2004).

Salomon no sólo creó una de las primeras escuelas de Trabajo Social, sino que trabajó por el desarrollo de una enseñanza de calidad y la internacionalización del trabajo social, ya que

${ }^{3}$ En 1908, le denegaron su doctorado y tuvo que recurrirlo para que se lo concediesen, mientras que en 1932 le condecoraron con un doctorado honoris causa, pero tras el ascenso de Hitler al poder en 1933, este y el resto de méritos le fueron arrebatados. El doctorado honoris causa se lo restituyeron en 1997 , obviamente cuando ya era demasiado tarde. 
concebía que si los problemas sociales eran consecuencia de un sistema económico global injusto, había que aplacarlo a través del esfuerzo conjunto del mayor número de profesionales de todos los países. Los contactos internacionales que inició primero su padre y que, posteriormente, continuó su hermano mayor influyeron en la vocación de Salomon por la cooperación internacional para solventar los problemas sociales globales.

Pese a que fue educada en una familia judía no practicante, la influencia del judaísmo en su concepción del trabajo social es muy importante. Es probable que esta influencia tenga que ver con su tardía conversión al cristianismo, en 1914, con el estrecho contacto que mantuvo con la comunidad judía como profesional de la intervención social, y con el carisma de su madrina intelectual, la trabajadora social y miembro de la junta directiva de la Sociedad de Cultura Ética de Berlín Jeanette Schwerin.

Muchos son los elementos destacables en este sentido: la importancia que tienen para ella el empoderamiento y la dignificación de las personas, la gestión estructural de los problemas sociales concretos, la siempre desinteresada responsabilidad individual y la responsabilidad de toda la sociedad en la lucha contra las desigualdades sociales, su capacidad de movilización de la acción pública y de la protección social en la reparación de injusticias a los más desfavorecidos, la dignificación del trabajo de los más pobres, la regulación de una educación digna y de calidad de las y los profesionales del trabajo social, y la promoción del voluntariado fueron, entre otros, elementos esenciales de la ética social y práctica de su trabajo social (Salomon, 1921, 1922, 1983; Lees, 2004) ${ }^{4}$ que se encuentran en plena sintonía con los valores preponderantes del judaísmo (Kuhlmann, 2008; Feustel, 2011, 2012). De entre todos ellos, nos centraremos en analizar su concepción de justicia social.

En plena sintonía con el consenso profesional de la época, Salomon denunció la donación de limosnas y

${ }^{4}$ En este sentido, cabe destacar la existencia del trabajo social judío, cuyos orígenes pre-profesionales se remontan a Nueva Ámsterdam (posteriormente denominada Nueva York) en 1654, y los profesionales, a 1916 en la misma ciudad. Si bien es cierto que se podrían encontrar elementos comunes entre el trabajo social judío y el trabajo social propuesto por Alice Salomon, consideramos que las múltiples diferencias de los dos contextos sociopolíticos, así como la distancia entre el practicado en Nueva York y el practicado en Berlín, resultan insalvables, por más que Salomon hubiese permanecido durante algunos meses en Nueva York en 1937, ya que su propuesta de trabajo social se encontraba ya perfectamente consolidada. De hecho, la formación para el trabajo social profesional en Alemania comienza su andadura en 1899 de la mano de Salomon, mientras que en Nueva York se iniciaría diecisiete años más tarde, con la creación de la Graduate School for Jewish Social Work, que se vio obligada a cerrar en 1939. Pese a la más que comprensible resistencia del que fuera su rector, el trabajo social judío estaba abocado a su desaparición. El implacable efecto que tuvo la creación de los servicios sociales públicos estadounidenses en la concepción de la pobreza, así como el apoyo que parte de la comunidad judía les propició ante la eclosión de grupos radicales antijudíos, fueron los principales detonantes del declive definitivo del trabajo social judío (Hidalgo, 2014). abogó por ayudar a la persona usuaria a ayudarse a sí misma (Schwerin, 1894 [cit. en Fassmann, 1996]; Zeller, 1998). En este sentido, resulta particularmente ilustrativa la concepción que Salomon tiene del estilo personal que cada profesional del trabajo social debe imprimir a la intervención social, el cual debe tener como finalidad el empoderamiento de la persona usuaria (1926a): hay que ser compasivo y empático para inspirar confianza, pero hay que ponerle límite a esta compasión a través de la adecuada distancia profesional (a la que hoy denominaríamos proximidad), evitando a toda costa la sobreprotección y el paternalismo para con la persona usuaria.

Dicho de otro modo, concibe que la compasión es importante a la hora de iniciar el proceso de ayuda y el asesoramiento al necesitado, pero posteriormente el profesional debe diagnosticar los problemas sociales de la persona afectada, por lo que debe tomar distancia. No en vano, Salomon concebía el cuidado y la atención de las personas usuarias como un riguroso proceso metodológico cuyo principal objetivo era el empoderamiento de éstas e insistía en que, para realizar unos adecuados planes de atención, el trabajo social debía basarse en la investigación.

Para Salomon, los problemas sociales de las personas usuarias son debidos fundamentalmente a sus dificultades para adaptarse a la realidad. De hecho, éste es el núcleo central de su trabajo social: ayudar a las personas usuarias a adaptarse a sus contextos más inmediatos, dotándolas de herramientas para que, en un futuro, sean capaces de adaptarse por sí mismas. Según ella, todas las personas poseemos esta capacidad; no obstante, se requiere de tiempo, trabajo y esfuerzo para poder desarrollarla. Así, el proceso de empoderamiento llegará a su fin cuando las personas usuarias dominen el arte de adaptarse a los nuevos contextos por sí mismas (Salomon, 1926b). Por ello es tan importante la investigación de las situaciones sociales en las que se encuentren estas personas, a través de un trabajo social científico.

\section{Estas personas deben ser socialmente}

diagnosticadas y, por ende, categorizadas, pero sin perder nunca de vista que la intervención social que se implemente debe realizarse de corazón, con un profundo sentimiento de generosidad (Salomon, 1921, 1926a). No es posible hacer trabajo social más que con el corazón, siendo para ella el signo más evidente de la preeminencia de la ética en la intervención social. Aunque defendía un trabajo social científico y riguroso, capaz de medir y dar respuesta a las situaciones de necesidad de las personas usuarias, entendía que sólo gracias a la ética se lograría identificar las injusticias sociales para erradicarlas.

Salomon pone el acento en la práctica con la persona usuaria más que en el conocimiento que se adquiere de ésta, haciendo propio el lema de Jane Addams 
de "actuar antes que todo saber" (Idareta, 2011), considerando que las relaciones con las personas usuarias deben ser cara a cara. No sólo es importante para la persona usuaria, porque, de este modo, el profesional le inspira confianza, sino también para el profesional, que toma contacto real, se relaciona con la persona usuaria y no con la idea que se pueda componer de aquélla. Además, se puede saber mucho sobre la persona usuaria, pero lo importante es el uso que se hace de dicho conocimiento, y en todo ello, según Salomon $(1903,1921,1922)$, la ética nos guía, asesora y alienta.

Por ello, los tres principios éticos que, según Salomon, han de orientar toda intervención social son los siguientes: no abusar de la persona usuaria, no manipularla ni intentar persuadirla, y no realizar juicios de valor sobre ella o su situación (Salomon, 1921, 1922, 1926a). En resumen, que hay que tratar a las personas usuarias como un fin y no como un medio, respetando en todo momento las decisiones que tomen en torno al logro de su bienestar. Hay que ayudarles de corazón a que se valgan por sí mismas y a que puedan hacerse cargo de sus vidas y de la provisión de recursos, a la par que se insta al Estado a que asuma su responsabilidad en la protección social de las personas más necesitadas (Salomon, 1896; Feustel, 1997).

Para Salomon, la justicia social es una idea regulativa a la que hay que aspirar en el trabajo social. Entiende que la justicia social es inalcanzable, pero que hay que esforzarse por aproximarse a ella cada día (Salomon, 1932; Lees, 2004). Concibe que las personas son iguales pero diferentes, por lo que si tratamos a todas por igual, podríamos incurrir en un tratamiento injusto. Por ello, el objetivo del trabajo social consistiría en tratar de forma diferente a todos los que son diferentes (Salomon, 1903) y en reparar las injusticias de diferente forma que la política social, ya que no es suficiente con proponer y aplicar políticas sociales o cumplir con las leyes vigentes: hay que ayudar a los más desfavorecidos a que puedan valerse por sí mismos, a subsistir por sus propios medios.

Luchar contra el individualismo, el egoísmo, las desigualdades y las injusticias es la esencia del trabajo social. La identidad del trabajo social se basa en dar con profesionalidad la mejor respuesta a las necesidades concretas de cada persona necesitada. Para Salomon (1933), la justicia social radica en la asunción de la responsabilidad para con los más débiles y, aunque cada ciudadano debe implicarse activamente en ello, aquélla debe estar controlada por el Estado como máximo garante y protector del bien y del interés común. Por ello, la justicia social no sólo depende de la responsabilidad de cada miembro de la comunidad, sino también de la responsabilidad del sistema político y económico.

En este sentido, Salomon considera que la pobreza, la miseria, el hambre, las desigualdades entre hombres y mujeres, la opresión o el patriarcado son problemas estructurales a escala mundial y consecuencia de un sistema económico injusto. De ahí que hubiese optado por aunar esfuerzos de otras y otros profesionales del trabajo social de otros países para erradicar este fenómeno opresivo y esclavizador, apelando a la solidaridad.

\section{Diferencias y similitudes entre la ética de Lévinas y Salomon: la tzedaká}

Los principales elementos de la ética judía son el compromiso y la acción para con el prójimo, la obligación de erradicar la pobreza y atender a los más desfavorecidos, la lucha contra la desigualdad, la responsabilidad individual y de la sociedad frente a los problemas sociales y la educación emocional en la toma de decisiones éticas. Tanto para Lévinas como para Salomon, estos elementos son centrales en sus propuestas éticas, por lo que, en este apartado concretaremos brevemente aspectos que se derivan de los anteriores y que diferencian o asemejan sus propuestas éticas. A partir de la concreción de tales aspectos, creemos que estaremos en disposición de afirmar si, como señalan Kuhlmann (2008) y Feustel (2011, 2012), la tzedaká es un elemento central en la propuesta de Salomon y si, efectivamente, lo es también para Lévinas.

Tanto para Lévinas como para Salomon, la ética es crucial en sus propuestas. Para el primero, la ética debe ser primera filosofía, y para la segunda, su preeminencia en relación con el resto de disciplinas resulta incuestionable. En este sentido, ambos tienen una considerable influencia del judaísmo. En el caso de Lévinas, el judaísmo es el sustrato latente de su filosofía, mientras que en el caso de Salomon, el paralelismo con el judaísmo es muy significativo, como hemos podido comprobar y como concretaremos a continuación.

Mientras que la denuncia de Lévinas se centra en la primacía de la tradición griega en la filosofía occidental y sus violentas consecuencias para la digna supervivencia de la alteridad (el egoísmo, el individualismo, la avaricia), Salomon denuncia las desigualdades entre hombres y mujeres y la desprotección que padecen los más desfavorecidos a consecuencia de un sistema económico y social injusto. Por ello, el propósito de ambos es una paz que erradique las injusticias de raíz. Ambos las conocían muy bien: eran judíos y padecieron las consecuencias del nazismo. De ahí que el objetivo principal, para Lévinas, fuese la defensa de la alteridad, y para Salomon, la igualdad entre hombres y mujeres, y la protección social de los más desfavorecidos.

La ética del trabajo social, en el caso de Salomon, es una ética social y práctica, preocupada por el establecimiento de normas básicas de convivencia digna y por solventar problemas sociales concretos de las personas más desfavorecidas. En el caso de 
Lévinas, también es una ética práctica 5 . Desde la perspectiva levinasiana, el profesional del trabajo social debe: respetar siempre la singularidad de la persona usuaria; ser sensible, a la par que mantenerse vigilante, ante las categorizaciones diagnósticas de la persona usuaria, siendo para ello fundamental el encuentro cara a cara con ésta; y, finalmente, dejar que la emoción inicie este proceso, sin llegar a desaparecer durante la categorización, para que podamos personalizar la intervención y proteger la singularidad de la persona usuaria (Idareta, 2011, 2012).

Por su parte, para Salomon es tan importante la compasión como la justicia; considera que el contacto directo con la persona usuaria durante la visita y el asesoramiento inspira confianza y, además, posibilita que el profesional no sólo conozca, sino que sienta a la persona usuaria; la acción precede al conocimiento de la persona usuaria y debe llevarse a cabo de corazón, debiendo ser, precisamente por ello, excelente, y buscar en todo momento ayudarla a valerse por sí misma.

En ambos autores, la gestión de las emociones en la toma de decisiones éticas es fundamental. Para Lévinas, la conmoción de entrañas del profesional y la respuesta a la persona usuaria se contempla en un mismo gesto de responsabilidad hacia ella, mientras que para Salomon la compasión, que posibilita un encuentro real y empático con la persona usuaria, deberá ser limitada por el profesional para salvaguardar la distancia profesional con la persona usuaria. En ambos casos, la responsabilidad del profesional para con ésta es muy elevada, aunque en el caso de Salomon sugiere un descanso sabático para poder guardar la distancia profesional pertinente tras la máxima implicación del trabajador social durante su ejercicio profesional.

Dicho de otro modo, lo que Salomon propone es que, inicialmente, nos relacionemos de forma directa con la persona usuaria y no a través del conocimiento que adquiramos de ella. Que lo que inicialmente prepondere sea la acción que surja del corazón. Esta implicación emocional, siempre controlada, traslada la inteligencia emocional que las y los profesionales del trabajo social deben desarrollar y cultivar. De hecho, para Salomon las injusticias han de sentirse, nos han de indignar para que luego podamos luchar por erradicarlas.

El componente emocional en la ética de la intervención social de Salomon tiene un peso específico muy importante a lo largo de su obra y encuentra su paralelismo en la práctica de la tzedaká judía: hay que sentir la injusticia del desfavorecido para luchar por erradicarla con la intervención social científica más rigurosa, y haciendo responsable al

5 Aunque reconoce que su ética no es programática (Lévinas, 2000; Poirié y Lévinas, 2009), nos basaremos en la aproximación que de ésta realiza Idareta al trabajo social $(2011,2012)$ para concretar más su propuesta ética.
Estado de la protección social del bien común. En este sentido, como veremos más adelante, Salomon también establece unos mínimos morales para la intervención social, que se resumen en uno: no tratar a la persona usuaria como un medio, sino como un fin, ayudándola de corazón a valerse por sí misma.

Para ambos, la educación es un elemento nuclear en la conformación de profesionales éticos. Para Lévinas, director de la Escuela Normal Israelí Oriental desde 1945, es el modo en que se forjan personas responsables, mientras que para Salomon, fundadora, directora y profesora de la primera escuela de Trabajo Social de la historia en 1908, la educación es la forma en la que se modela a las personas con buen corazón. Queda así patente la importancia de la ética para ambos. No obstante, para ambos también, la ciencia es fundamental. Tanto para Lévinas como para Salomon, resulta imprescindible el rigor y la exhaustividad de la ciencia. A ambos también la preponderancia de la ética les lleva a ser prudentes y cautelosos: Lévinas insta a descategorizar lo categorizado, y Salomon insiste en que no es cuestión de saber mucho, sino de saber emplear el conocimiento. En ambos casos, la ética se encuentra en la base de la ciencia, para orientarla y guiarla.

Tanto para Lévinas como para Salomon, la práctica de la tzedaká o la exigencia moral de la reparación de la injusticia social es consustancial a sus propuestas éticas: mientras que el primero propone lograrlo salvaguardando la singularidad del Otro, la segunda propone erradicar la desigualdad entre hombres y mujeres, y ayudar a los más desfavorecidos a través de su empoderamiento. Lévinas concibe la compasión como sensibilidad que urge a responder al Otro, mientras que Salomon la considera como un don del profesional que inspira confianza y que humaniza la intervención social.

Ambos denuncian la donación de limosna: Lévinas afirma que el Otro nos reclama a cada uno de nosotros, y no nuestras limosnas, mientras que Salomon considera que lo más importante que se les podría ofrecer a los más necesitados era su autosustentación. Precisamente por ello, ambas perspectivas encajan en el grado más elevado de caridad de la escala de tzedaká propuesta por Maimónides. Del mismo modo, contemplan la justicia social como modo de universalizar, proteger, garantizar y promover el empoderamiento de cada persona: Lévinas, proponiendo la sensibilidad vigilante que descategoriza lo categorizado; y Salomon, contemplando que hay que empoderar a los más necesitados, tratándolos de forma diferente si son diferentes.

Las propuestas éticas de cada autor apuntan en la misma línea: Lévinas aboga por que no se puede no responder a la alteridad, de modo que considera que es capital la responsabilidad infinita para con el Otro; mientras que Salomon concreta tres principios básicos (no abusar, no manipular y no enjuiciar a la 
persona del usuario), que se resumen en no tratar a la persona usuaria como medio, sino como un fin. Es por ello por lo que, en ambos casos, estamos, hablando de una ética práctica, centrada en la solución de los problemas sociales concretos, y de una ética de la responsabilidad ${ }^{6}$.

Del mismo modo, ambos establecen las bases para la conformación de una ética de mínimos morales comunes que delimitan el umbral de la dignidad humana en el trabajo social. Lévinas apunta a que hay que evitar la violencia que se ejerza a través de la categorización definitiva. Por ello, antes de cualquier operación ontológica de cálculo, medida y comparación, y como inalienable fundamento de aquélla, se encuentra la irreductibilidad de la alteridad, que es, para Lévinas, la que señala el límite de la dignidad humana, que ha de ser salvaguardada por el Estado.

Antes, durante y después del diseño o de la implementación de las operaciones por medio de las que tendemos a catalogar y a categorizar a la persona usuaria y su situación social (diagnóstico social, valoración del cumplimiento de criterios para la concesión de prestaciones o ayudas, evaluación de su situación social, planificación de una intervención social, supervisión y seguimiento del caso, información sobre el caso, investigación sobre el colectivo y sus problemas), la persona usuaria disfruta de su intransferible y exclusiva irreductibilidad, ya que ésta es anterior a todas ellas.

Por su parte, Salomon señala que hay que tratar a la persona usuaria como un fin en sí mismo, sin abusar de ella, ni manipularla, ni enjuiciarla. El umbral de indignidad para Salomon pasa por no cosificar a la persona usuaria, ni tratarla como medio para lograr nuestros propios fines e intereses. Las y los profesionales del trabajo social han de ayudar a los más desfavorecidos a alcanzar el umbral de dignidad que, según Salomon, se logra haciendo que la persona usuaria pueda valerse por sí misma. Cuando ésta se sepa y se sienta capaz de proveerse de su bienestar con autonomía, podremos hablar de que ha adquirido conciencia de su propia dignidad.

Por ello, para Salomon la conciencia de la dignidad de la persona viene de la mano de la adquisición de su emporaderamiento, que se torna obligación moral para todo profesional del trabajo social. Dicho de otro modo, el empoderamiento de la persona usuaria es obligación moral de todo profesional, y lo será hasta que aquélla no lo haya adquirido y se encuentre bajo la tutela de éste. Así, la trabajadora o trabajador social tiene el deber moral de ayudar a la persona usuaria que se encuentre por debajo del umbral de la dignidad, garantizándosela a través de la adquisición de su empoderamiento para que, a partir de ahí, pueda autosustentarse por sí misma.

${ }^{6}$ Aunque, en el caso de Salomon, hay quien señala que su propuesta pueda también tener que ver con la ética del cuidado (Kuhlmann, 2008).

\section{Conclusiones}

A tenor de lo anteriormente señalado, queda patente la influencia del judaísmo en las aportaciones de Lévinas y de Salomon, especialmente a través de la identificación de la tzedaká en sus concepciones de justicia social. Para Lévinas, aunque la justicia compare, mida, calcule y categorice a los ciudadanos, la trabajadora o trabajador social debe preocuparse posteriormente de descategorizarlos o de contemplarlos irreductibles en su categorización. Según Lévinas, "la justicia es despertada por la caridad, pero la caridad, que es antes que la justicia, está también después de ella" (Poirié y Lévinas, 2009: 82).

En la ética de Alice Salomon, la compasión y la justicia son dos elementos fundamentales. La compasión posibilita una experiencia real con la vulnerabilidad de los más desfavorecidos. La compasión significa que la vulnerabilidad del necesitado nos toca el corazón y nos hace sentirnos también vulnerables. Es por ello por lo que Salomon propone que, en ese estado de vulnerabilidad de la persona usuaria, las y los profesionales del trabajo social no la enjuiciemos, abusando de nuestro poder e intentado persuadirla para alcanzar nuestros intereses personales.

Cabría, por tanto, concluir que ambas aportaciones establecen las bases para la conformación de una ética de mínimos en el trabajo social que salvaguarda la dignidad y la moralidad humana. Para Lévinas, si la irreductibilidad de la persona y, por tanto, su dignidad como tal, es anterior a toda operación ontológica por medio de la que se la tiende a catalogar, es obligación moral del profesional del trabajo social respetarla y protegerla, devolviendo a la persona a este estado preontológico tras cada categorización. En este sentido, Lévinas advierte que, cuando se categoriza al Otro, no se le está tratando como persona irreductible. Precisamente por ello, el profesional debe mantenerse vigilante para preservar la dignidad de la persona usuaria, especialmente, durante estas operaciones ontológicas de cálculo, medida y comparación, donde se corre más peligro de violentarla, aunque, de igual modo, antes y después de llevarlas a cabo.

Para Salomon, el umbral de dignidad consiste en tratar a la persona usuaria como fin en sí misma, lo que se traduce para la trabajadora o trabajador social en la obligación moral de empoderarla. No es suficiente con proveerla de recursos y hacerlo de corazón. Si la empoderamos, ella misma defenderá su propia dignidad y, con el tiempo, puede que la de los demás seres humanos, puesto que empoderar también significa, para Salomon, concienciar de que la gran mayoría de los problemas sociales son estructurales y de que hay asumir individual y colectivamente la responsabilidad de los problemas sociales que nos afectan a todos, tratando a todos los que son diferentes de modo diferente. 
En definitiva, según Lévinas y Salomon, la irreductibilidad de la persona usuaria a cualquier categoría ontológica, así como el empoderamiento y la consiguiente toma de conciencia de la dignidad humana de la persona usuaria, serían, respectivamente, las obligaciones éticas del profesional, a la par que los límites infranqueables. Límites que, de transgredirse, supondrían un trato inhumano en el curso de nuestra intervención social o en la omisión de ésta. Éste es motivo suficiente para que el trabajo social y las disciplinas afines no cejen en su empeño de reflexionar sobre tales límites y sobre si, efectivamente, la dignidad que se propone preserva a la persona por el simple hecho de serlo.
Para el trabajo social, es un imperativo ético insoslayable que se agudiza, si cabe, mucho más con motivo de los vertiginosos cambios estructurales y de los nuevos fenómenos y acontecimientos sociales que precipitan la construcción de nuevos paradigmas $y$, por ende, nuevas concepciones de la dignidad humana en las diferentes sociedades del mundo. Precisamente por ello, y del mismo modo que Lévinas y Salomon, nosotros también apelamos una y otra vez al indiscutible fundamento que a cada momento ayuda a reflexionar, a delinear y a actualizar los límites que aseguran la integridad y la dignidad humana: la ética. 
BAECK, L. (1960): Vom Wesen des Judentums, Colonia, Melzer.

BRAVERMAN, R. (2014): Lévinas: de la morada a la justicia, Lima, Fondo Editorial.

COHEN, H. (2004): La religión de la razón desde las fuentes del judaísmo, Barcelona, Anthropos.

CORTINA, A. (2010): Justicia cordial, Madrid, serie Minima Trotta, Trotta.

CRITCHLEY, S. (2004): “Emmanuel Lévinas. Un inventario dispar”, en BARROSO, M.; y PÉREZ CHICO, D. (eds.), Un libro de huellas. Aproximaciones al pensamiento de Emmanuel Lévinas, Madrid, Trotta, págs. 315-329.

DE LANGE, N. (1996): Judaísmo, Barcelona, Riopiedras.

FACKENHEIM, E. L. (2005): ¿Qué es el judaísmo?, Buenos Aires, Fundación David Calles para la Difusión del Humanismo.

FASSMANN, I. M. (1996): Jüdinnen in der deutschen Frauenbewegung 1865-1919, Hildesheim; Zurich; Nueva York, Olms.

FEUSTEL, A. (2012): "Pioneering social worker Alice Salomon", Journal of Social Intervention. Theory and Practice, vol. 21, nํ 4, págs. 89-94.

- (2011): Das Konzept des Sozialen im Werk von Alice Salomon, Berlín, Metropol.

- (2006): "The significance of international relations and cooperation in the works of Alice Salomon", Ariadne. Forum für Frauen- und Geschlechtergeschichte, vol. 49, págs. 24-29.

- (2004): Alice Salomon. Frauenemanzipation und soziale Verantwortung - Ausgewählte Schriften in drei Bänden, vol. 3 [1919-1948], Munich, Luchterhand.
- (2000): Alice Salomon. Frauenemanzipation und soziale Verantwortung - Ausgewählte Schriften in drei Bänden, vol. 2 [1908-1919], Berlín, Neuwied.

- (1997): Alice Salomon. Frauenemanzipation und soziale Verantwortung - Ausgewählte Schriften in drei Bänden, vol. 1 [1896-1908], Berlín, Neuwied.

HIDALGO, A. (2014): “El trabajo social ‘judío’ y su contribución a la configuración del Trabajo Social general como profesión y disciplina. Una primera aproximación científico-filosófica", Cuadernos de Trabajo Social, vol. 27, nㅜㄹ, págs. 187-195.

IDARETA, F. (2012): “La Ética como primera filosofía en Irena Sendler y Alice Salomon: antecedentes prácticos de la Ética de Emmanuel Lévinas en el Trabajo Social", Humanismo y Trabajo Social, vol. 11, págs. 119-140.

- (2011): Ética como primera filosofía: aproximación de la ética de E. Lévinas al Trabajo Social, Saarbrücken, Editorial Académica Española.

KELLNER, M. (1995): “La ética judía”, en SINGER, P., Compendio de ética, Madrid, Alianza.

KLIKSBERG, B. (2000): El judaísmo y su lucha por la Justicia Social, Buenos Aires, Fondo de Cultura Económica.

KUHLMANN, C. (2008): "Alice Salomon (Germany), President 1928/29 - 1946", Social Work \& Society, vol. 6, nำ 1.
- (2007): Alice Salomon und der Beginn sozialer Berufsausbildung: Eine Biographie, Deutsch, Ibidem.

- (2001): "Historical portraits of important European leaders in social work: Alice Salomon (18721948). Germany", European Journal of Social Work, vol. 4, no 1 , págs. $65-75$. 
- (2000): Alice Salomon. Ihr Beitrag zur Entwicklung der Theorie und Praxis Sozialer Arbeit, Weinheim, Deutscher Studien-Verlag.

LEES, A. (2004): Character is Destiny. The Autobiography of Alice Salomon, Ann Arbor, The University of Michigan Press.

LÉVINAS, E. (2006a): Más allá del versículo: lecturas y discursos talmúdicos, Buenos Aires, Lilmod.

- (2006b): “Paz y proximidad”, Revista Laguna, nํ18, págs. 143-151.

- (2004): Difícil libertad, Madrid, Caparrós Editores.

- (2003): De otro modo que ser o más allá de la esencia, Salamanca, Sígueme.

- (2002): Totalidad e infinito, Salamanca, Sígueme.

- (2000): Ética e infinito, Madrid, Machado Libros.

- (1997): Fuera del sujeto, Madrid, Caparrós Editores.

- (1996): Cuatro lecturas talmúdicas, Barcelona, Riopiedras.

- (1994): Los imprevistos de la historia, Salamanca, Sígueme.

NOGAL, E. (2008): “Alice Salomon. 1872-1948”, Trabajo

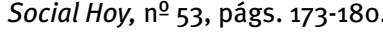

PEYSER, D. (1958): “Alice Salomon. Ein Lebensbild”, en MUTHESIUS, H. (ed.), Alice Salomon. Die Begründerin des sozialen Frauenberufs in Deutschland, Colonia, Carl Heymanns Verlag.

POIRIÉ, F.; y LÉVINAS, E. (2009): Ensayo y conversaciones, Madrid, Arena Libros.

SALOMON, A. (1983): Charakter ist Schicksal, Lebenserinnerungen, Weinheim, Beltz.

- (1933): “Die Anfänge der Arbeit sozialen”, Die Frau, vol. 12, págs. 723-725.
- (1932): Soziale Führer. Ihr Leben, ihre Lehren, ihre Werke, Leipzig, Quelle\&Meyer.

- (1926b): "Zur Theorie des Helfens", Wohlfahrt und Sozialhygiene, vol. 5, no 2, págs. 4-13.

- (1926a): “Soziale Diagnose”, en FEUSTEL, A. (ed.) (2004), Alice Salomon. Frauenemanzipation und soziale Verantwortung. Ausgewählte Schriften in drei Bänden, vol. 3, Munich, Luchterhand.

- (1922): "Die sittlichen Grundlagen und Ziele der Wohlfahrtspflege”, Soziale Berufsarbeit, vol. 11, págs. 41-44.

- (1921): “Die sittlichen Grundlagen und Ziele der Wohlfahrtspflege", en MUTHESIUS, H. (ed.), Alice Salomon. Die Begründerin des sozialen Frauenberufs in Deutschland, Colonia, Carl Heymanns Verlag.

- (1903): “Die Herabsetzung der Arbeitszeit für Frauen”, Die Frau, vol. 4, págs. 200-205.

- (1896): “Das Kaiser und Kaiserin Friedrich Kinderheim in Bornstedt”, Die Frau, vol. 1, págs. 11-19.

SCHRÖDER, I. (2010): Alice Salomon und ihre Bedeutung für die Soziale Arbeit, Munich, GRIN Verlag.

SUCASAS, A. (2006): Levinas: lectura de un palimpsesto, Buenos Aires, Lilmod.

WIELER, J. (1997): "El impacto de Alice Salomon en la enseñanza del Trabajo Social”, Trabajo Social y Salud, no 26, págs. 9-24.

- (1988): "Alice Salomon", Journal of Teaching in Social Work, vol. 2, no 2, págs. 165-171.

ZELLER, S. (1998): “Nicht Almosen, sondern Gerechtigkeit. Jüdische Ethik und ihrehistorischen Wurzeln für die Professionalisierung in der Sozialen Arbeit”, Neue Praxis, vol. 28, nำ6, págs. 540-556. 